\title{
REVIEW | The Creative Echo Chamber: Contemporary Music Production in Kingston, Jamaica.
}

\author{
Dennis O. Howard
}

Kingston: Ian Randle Publishers, 2016

ISBN: 9789766378943 (PB)

\section{Donald W. Harper}

Beijing Institute of Technology

dwh_bryantzhuhai@outlook.com

Howard's treatise on music production techniques in Jamaica is a comprehensive scholarly work with the bold agenda, "to examine the Jamaican music business from its inception in the early 1950s to ascertain the economic, social, legal and international structures which affected its development" (xv). To do the expected heavy analytical lifting, he outlines an extensive multi-disciplinary framework that serves as a deux ex machina that will assist him in conducting the analysis, coining the term "creative echo chamber" as its central "theoretical device" (xxi).

Howard opens the discussion by bemoaning the extent to which Jamaica has yet to realize any measurable economic benefits from its creative musical output. Whilst Kingston's reputation as a music mecca is well established, he builds upon the work of Power and Hallencreutz (2002) and Hebdige (2003) to demonstrate Jamaica's shortcomings. One reason, Howard reminds us, is that historically, Jamaica has struggled with implementing an effective intellectual property rights infrastructure. He also concurs with Kozul-Wright and Stanbury's (1998) the findings of Power and Hallencreutz's (2002) that a significant debilitating culprit is the fragmented nature of the small, entrepreneurial-type production firms. While these firms are responsible for much of the acclaim attributed to Jamaica's music, Howard contends that they were not privy to conventional modes of operation 
and "were neither prepared nor equipped to take on the management of talent in a professional context" (3). He wants us to know why.

Rather than focusing on the Jamaican industry's economic shortcomings, Howard has a different agenda. He argues that despite the acknowledged industry deficiencies, Jamaican music practitioners "have also managed to create new business models and modes of creativity centred on a non-Western cosmology, hybrid construction and hegemonic and counterhegemonic ripples" (xvi). A crucial point for Howard is that to grasp the dynamics of popular music production in Kingston, we are required to confront "the social, legal and economic milieu which existed in the colonial and postcolonial periods within which it was produced" (xvi). This perspective should resonate with the interests of postcolonial and plantation economy researchers.

Howard seems to recognize the complexity and the arduousness of the effort. Much of the introduction is occupied with an attempt to construct an analytical mechanism that he systematically threads together by drawing upon a mosaic of relevant disciplines. Fundamentally, he aims to carve his model within an "AfroCaribbean aesthetic" (xxi), ensuring that the model has a sociological orientation to the socio-cultural and socio-historical dynamics of the Jamaican music arena. As a Jamaican who confesses to extensive intimate-insider knowledge of the Jamaican music industry, he feels justified in relying upon auto-ethnography to do the methodological work. He is clear on the book's target audience. Anyone with "specialist interests in Jamaican popular music" (9) should not only find the book an interesting read but, if read closely, they should also find significant benefit from Howard's personal and documentary accounts of key moments that are relevant to understanding the evolution of the industry.

He proceeds to ground his framework upon two foundational pillars: ethnomusicology and cultural studies, and invokes elements from Peterson's (1982) production of culture perspective as a way to remind us that culture is never created solely by the genius of the individual. As researchers should also aim to contextualize their analyses, Howard argues that they must remain alert to how cultural producers' roles and identities are configured by social and institutional structures of the milieu in which they find themselves.

The analysis further draws upon soundscape studies and popular music studies for some additional theoretical leverage. In applying the former, it gives him the license to provide an account of the evolution of the sounds and production techniques that became hallmarks of the Jamaican musical genres: reggae, dub and dancehall. However, it is the awareness of the simultaneity of forces that should enable this publication to contribute to popular music studies in a significant way. Howard invites us to take account of how a particular set of political, economic, and social forces, riddled with tension, not only contributed to the under-development of Jamaican music. Those same sets of forces contain the clues to understanding Jamaican music's far-reaching influence on the global music landscape. Howard laments the paucity of scholarly work on Jamaican music and assails existing literature for their myopic North Atlantic perspective. In particular, he charges them with paying inadequate attention to role played by sound systems, the dub-plate culture and the jukebox in the development of Jamaican music. 
Howard's work on the Jamaican music industry deserves applause. His insider knowledge of the Jamaican music industry is deep and extensive, and it shows. This is particularly evident in Chapter 3, "Making Popular Music in the Creative Echo Chamber", and again in Chapter 6 "Tek-no-li-gy Processing: Reshaping the Soundscape". These chapters are the book's strong points, making a major contribution to the field. Chapter 6 for instance, undertakes a painstaking, meticulous analysis that shows how Jamaican studio engineers, such as Osbourne "King Tubby" Ruddock and Lee "Scratch" Perry, designed production techniques that ultimately were "used by producers and engineers of innumerable pop genres including techno, house, hip hop, dance, trance, reggae-ton and ambient" (173).

The vision Howard displays with the proposed multidisciplinary theoretical device holds much promise, in which the creative echo chamber is, "simultaneously, physical space, discrete methodologies, mythologies and intangible mechanisms, which are responsible for the 'cross rhythms' of Caribbean culture" (xxi). This definition gives the impression that the device is meant to do quite a bit of work but it is less clear how such a device should be applied, and the form that a corresponding analysis should take. As the book covers a lot of ground, perhaps the model is overtasked.

For instance, the creative echo chamber can be articulated through three distinctive dimensions: "Geospatiality, Repetition and Communality" (xxi). Yet, how they are systematically deployed in his analyses seem underplayed throughout. The model's theoretical framework is within all of eight pages, yet a comparative silence on the theoretical triad both limits their contribution and limits the potential here to offer as a forceful theoretical foray in popular music studies. In turn, this raises the question to what the extent the creative echo chamber' does duty here as an analytic model. Or, is it simply a term we can use, albeit an appropriate one, to describe Kingston's musical domain? Unless Howard follows up on this work with a more robust application of the model, the answer appears uncertain.

Regardless, the book does important work. It should serve as a useful resource for music enthusiasts and policy makers who have a specific interest in the Jamaican music industry. But, in targeting such a specialized audience, a golden opportunity may have been missed. This work, if repositioned, could contribute to the scholarship on cultural sectors on a much broader global scale because, as Hesmondhalgh and Pratt (2005) remind us, there is an international dimension to cultural policy. Popular music studies in particular has much to gain from engaging with a vast range of cultural and artistic practices that take place in farflung global corners. A work such as this could contribute greatly to a better understanding of the kinds of cross-border cultural and economic engagements they inspire.

Having gained a better understanding of the tensions inherent in the dynamics of Kingston's creative echo chamber, I was curious to gain some insight as to how Jamaica might address them moving forward. Howard seems to echo plantation economy theorist George Beckford (1972), by calling for a "radical departure from Eurocentric solutions to a Creole reality" (184). We discover that, while Howard's principle is clear, his specifics leave us wanting. He says that "Eurocentric orientation, combined with North Atlantic geopolitics, is at the root of our economic development" (184), arguing for institutional frameworks "to take place 
within the unique sociocultural space which is occupied by the industry" (184), but details about these frameworks are left to be tackled by his cursory discussion on future research initiatives. I am concerned that his recommendations did not go far enough. He wraps up the book by stating that, "the cultural industries with music at the centre will be an important consideration of the way forward if true economic development is to be realised" (184). Hopefully then, this book sets the stage for more practical solutions to be devised for Jamaica.

\section{References}

Beckford, G.L. 1972. Persistent Poverty: Underdevelopment in Plantation Economies of the Third World. Oxford: Oxford University Press.

Hebdige, D. 2003. Cut'n'Mix: Culture, Identity and Caribbean Music. London: Routledge.

Hesmondhalgh, D. and Pratt, A.C. 2005. Cultural Industries and Cultural Policy. International Journal of Cultural Policy 11(1): 1-13.

Kozul-Wright, Z. and Stanbury, L., 1998. Becoming a Globally Competitive Player: The Case of the Music Industry in Jamaica. United Nations Conference on Trade and Development, NCTAD Discussion Papers 138.

Peterson, R.A., 1982. Five Constraints on the Production of Culture: Law, Technology, Market, Organizational Structure and Occupational Careers. The Journal of Popular Culture 16(2): 143-153.

Power, D. and Hallencreutz, D., 2002. Profiting from Creativity? The Music Industry in Stockholm, Sweden and Kingston, Jamaica. Environment and Planning A 34(10): 1833-1854. 